\title{
Business education and erosion of character
}

ABSTRACT. This article discusses the evidence for the claim that exposure to the economic model of man tends to make students more selfish. It also discusses the more general problems created by the employment of the models of human beings used in the social sciences, which often are extremely simple, in business education.

After considering some proposed solutions to these problems, the article advocates exposing students to more inclusive conceptions of human nature and, as each model is taught, helping students to reflect on the aspects of our knowledge which it leaves out of account.

Key words: business education, economics education, models, human nature, business curriculum

\section{Introduction}

During the last 25 years literature has appeared that purports to show that business education makes students more selfish and that the reason for this is their repeated exposure to the economic model of human beings that depicts them as rational maximisers of individual utility. After reviewing this literature and the criticisms that have been addressed to it I conclude that its main claims appear to be well established.

I also argue that there is a more general problem as business students are also repeatedly exposed to other models of human beings that share with the economic model the feature of being highly reductive.

Obviously such claims raise serious issues about the activities of business schools. In the second half of this article I examine and criticise some proposals, which have been put forward for dealing with these problems, and recommend strategies that in my view have better prospects of success.

\section{Training in business or economics can be bad for your character}

During the last wave of business scandals accusing fingers were pointed in the direction of business educators (e.g. Mangan, 2002; Mitroff, 2004; Ghoshal, 2005). Critics claimed that part of the blame for the unethical behaviour of so many business leaders should be laid at the feet of business schools, as they had

Juan Elegido is Dean and Professor of Business Ethics at the Lagos Business School. His research interests focus on normative aspects of business ethics. obviously failed to instill in their students the ethical values and norms that would have helped them to conduct their professional activity with a due sense of responsibility.

This was not the first time that a wave of business scandals had hit the headlines and business schools had been blamed for them. However, something was different this time. Traditionally, critics had argued that business schools did not devote enough attention to business ethics, but now the complaints were more radical. The problem, as some saw it, was that the very substance of what was taught in business schools tended to make students selfish and immoral.

The evidence for this claim had been accumulating for over 20 years. A large number of empirical studies show that, in comparison with students of other disciplines, business students tend to behave in more selfish ways. I will review here only the more noteworthy among these studies. Some of these studies were done with business students while others investigated students of economics. I will make reference to all of the studies as the issue that concerns me is the effect that exposure to the economic model of human beings has on the students who are taught it and both economics and business students meet such model frequently in the course of their training. From a practical point of view, however, the focus of my interest is business students and I will refer exclusively to them in later sections of this article.

Attention was originally drawn to this issue by an article by Marwell and Ames (1981) in which it was reported that when compared with students of other disciplines, economics students had been found to freeride much more frequently in experiments that called for private contributions to public goods. Then Kahneman et al. (1986) and Carter and Irons (1991) found that economics and business students were more likely than other students to be selfish and take advantage of their position when sharing money with others. Sargent (1986) and Davis (1987) reported that business students scored lower than other students on moral development and that over their years in college, non-business students underwent significant moral growth, while business majors either did not develop or even regressed. Frank et al. (1993) reported that the proportion of professors of economics who declared that they contributed nothing to charities was more than double that of professors of any other discipline; and that economics students had much higher rates of defection in prisoner dilemma games played for money; and were less likely to report that they had received a larger quantity of goods than 
they had ordered (and were to pay for). Williams et al. (2000) found that having a higher proportion of MBAs among the members of their management teams made it more likely that firms would breach safety and health regulations. Frey and Meier (2003) reported that economics and business students in the University of Zurich contributed less than other students to two social funds set up by the university to support needy students. Rubinstein (2006) found that economics and MBA students were more ready to increase a company's profits by laying off a significant proportion of its workforce during a period of economic recession in which there is high unemployment.

Also, it has been shown that, when compared with students of other disciplines, economics and/or business students cheated more frequently in examinations (McCabe et al., 2006); were less willing to share a proportion of the winnings of a game with other members of their groups (Selten \& Ockenfels, 1998); were less ready to contribute to a common fund for mutual benefit (Cadsby \& Maynes, 1998); were more willing to accept a bribe in selecting a supplier for a students' club (Frank \& Schulze, 2000); and attributed more importance to values such as power, achievement and hedonism and less importance to universalism (Gandal et al., 2005).

Professors of business and economics have not been ready to accept without a fight that the net effect of their efforts is to worsen the character of their students. The above findings have been subjected to two main lines of criticism. The first centres on the reliability of the results themselves. It has been argued that not all the empirical results point in the same direction. Thus, the article by Frank et al. (1993) in which it was found that economics professors donate less to charities also stated that professors of economics differed little from their colleagues in other disciplines in terms of the number of hours spent in volunteer activities and voting in presidential elections. Other articles reported results more favourable to economics and business students. Thus, Yezer et al. (1996) found that envelopes containing money that were left in rooms about to be occupied by economics students were slightly more likely to be returned than envelopes left in rooms about to be occupied by students of other disciplines. It has also been argued that some of the articles cited above suffered from methodological faults; most significantly, that some failed to take into account the proportion of males and females in the different experimental groups (females have been reported to behave more cooperatively in some of these studies (Frank et al, 1993; Selten \& Ockenfelds, 1998)), and that others left room for ambiguity as to what is fair, all things considered, under the circumstances of the survey or experiment

The second line of criticism contends that several experiments and/or surveys, including most of the early ones, did not explore the possible causes of the differences observed between economics and business students and students of other disciplines. Was the more selfish behaviour of students of economics and business due to the training they had received (this has come to be called the 'indoctrination hypothesis')? Or was it the case that more selfish students are attracted to these disciplines (this is often called the 'selfselection hypothesis')? The self-selection hypothesis is rendered more plausible by the fact that it is well established that people typically choose environments and organisations which are congruent with their interests, goals and values (Schneider, 1987; Walsh \& Holland, 1992; Schneider et al., 1995) and by the fact that four of the studies cited above found evidence both for self-selection and indoctrination factors (Sargent, 1986; Davis 1987; Frank et al., 1993; Gandal et al., 2005) while two (Frank \& Schulze, 2000; Frey \& Meier, 2003) found evidence for self-selection factors and no evidence for indoctrination factors.

To weigh in detail all the arguments and counterarguments that have been raised in this discussion would require a full review article. However, the following is a summary of can be learned from the literature reviewed in relation to the present concerns:

(i) Despite the above criticisms, it seems overwhelmingly clear that business and economics students exhibit behaviours, which are significantly more self-centered than students of other disciplines. More recent articles have paid explicit attention to the methodological flaws that were identified in some of the early ones and have still reached the same conclusions; and while some articles have reported different results, it is fair to say that a large majority of the studies (and precisely those in which a larger number of subjects was examined) converge on the conclusion I report here (Marwell \& Ames, 1981; Carter \& Irons, 1991; Frank \& Schulze, 2000; Frey \& Meier, 2003).

(ii) The issue of self-selection versus indoctrination is more complex. It is clear that there is a selfselection effect, but whether or not there is also an indoctrination effect is not so clear-cut. As pointed out above, two studies (Frank \& Schulze, 2000; Frey \& Meier, 2003) failed to find evidence for indoctrination factors. However, against this, five studies in this area of research (Sargent, 1986; Davis, 1987; Frank et al., 1993; Blais \& Young, 1999; Gandal et al., 2005) and two in closely related areas (Tetlock, 2000; Aspen Institute, 2001) did find such evidence. Indoctrination seems to be at work and it follows from this that, as a consequence of their studies, many students may well be leaving business school more selfish and self-centered than they were when they gained admission into it.

Up to this point, I have relied exclusively on a review of systematic research. It is also interesting that, independently of this research, veteran educators have also called attention to this problem on the basis of their 
own experience. Thus, Leavitt (1989), Brennan (1994), Mangan (2002), Mintzberg (2004), Goshal (2005), and Ferraro et al. (2005), among others, have also denounced the negative effect of business education on the values of business students in articles that have been widely discussed.

\section{The neo-classical economic model of man}

As I pointed out above, my main interest is with business schools, so I will now try to be more specific in suggesting how business students are influenced in the ways described in the preceding section. The fundamental point is that a person's conception of human nature is bound to produce significant consequences (Simon, 1985; Jensen, 1994; Tetlock, 2000); the decisions people make on many important issues will ultimately depend on that conception.

While the immense majority of business schools teach very little to their students explicitly and positively about the nature of human beings, in many of the courses of a typical business programme, the economic model of human beings is taken for granted. Most business students are confronted repeatedly in the course of their studies with theories that are based squarely on that model. They take courses in Macroeconomics, Finance, and Strategy, to refer only to the most obvious instances, and these courses are almost certain to be heavily based on the methodology and assumptions of economics for the very simple reason that most of the serious, systematic work that has been done in those disciplines has used the methodology of economics. They are also likely to meet material that shares the same economic pedigree in other courses such as Accountancy, Marketing, Operations and even Business Law.

I have just referred to the economic model of human beings. We all use models in our thinking, if only because our ideas about any given reality are bound to be simplified and incomplete. Our knowledge cannot possibly exhaust the full reality of anything. However, when scientists build models, they simplify much more radically. Thus, for instance, most economists are well aware that emotions have an impact on the decisions of human beings; however, for the purpose of economic analysis, many of them leave aside that knowledge and assume that men are perfectly rational in the way they process information. I will discuss briefly below why economists act in this way. At this point, it will be enough to make the point that our common-sense models of human beings, the ones we use in making decisions in our daily lives, are typically much richer and broader than the models social scientists use in their work.

When I said above that business students are exposed in their studies to the economic model of human beings repeatedly, I was referring more specifically to the model of human beings used in neo-classical economics. It is true that one can find other schools of thought among contemporary economists, such as behavioural economics, feminist economics, new institutional economics and evolutionary economics to name only some of the more prominent ones, and these schools often use different models of human beings. And even within the main tradition of neo-classical economics, there are different interpretations. However, for the purpose of this paper, it is the traditional homo economicus model, and more specifically its traits of rationality and self-interest, that interest us.

The reason for concentrating on the traditional homo economicus model is that, as Ferraro et al. have pointed out, 'the large majority of the models presented to the students start with the traditional assumptions of economic theory' (2005:11), that is to say, as they make clear in their article, with the homo economicus model. Kahneman, a leading representative of behavioural economics concurs with this assessment when he observes that ' $[\mathrm{t}]$ he same assumptions are still in place as the cornerstones of economic analysis' (2003:162). He is also referring to the assumptions embodied in the homo economicus model.

That model is simple and very well defined. It portrays economic agents as rational agents who consistently seek to maximise their individual utility.

Each of the main features of this model are, to some extent, subject to different interpretations by various economists. We will concentrate here, however, on basic areas of agreement among these competing interpretations within the mainstream of neo-classical economics. Rationality in this model means at least that the decisions of economic actors are logically consistent over time, and that the pull of emotions or of social bonds is not allowed to swerve agents from trying to maximise their utility functions. Individual utility can for our present purposes be understood without significant distortion as self-interest. Nobel laureate Amartya Sen stated in an influential article that ' $\mathrm{t}]$ he first principle of Economics is that every agent is actuated only by self-interest' (1977:317) and Heinrich et al. have stated that the idea that people are entirely self-interested is a 'canonical assumption' (2001:73) in economics.

In relation to the topic of this article, the problem that this model of economic man poses is that when students are repeatedly exposed to it, they tend to end up viewing it not just as a model - and an extremely simplified one at that - but as a complete description of human nature. Two important consequences are likely to follow from this: (i) Students will come to expect that other people will act that way. This has clear practical consequences because it is well established in prisoner dilemma experiments that most subjects will defect if they are told that their partners are going to defect (Dawes, 1980). In other words, the mere fact that people expect that others will behave selfishly will tend to make them behave selfishly (Miller, 1999). 
(ii) They are likely to slide smoothly from the belief that 'this is the way most people act' to 'this is the normal way of acting', and from the latter to 'this is the way in which people ought to act' (Ferraro et al., 2005). Of course, any logician will be able to point out that this is a textbook example of illicitly moving from 'is' to 'ought', or from a descriptive to a normative statement. Unfortunately business students do not meet many logicians in the course of their studies.

\section{The effect of other models of human beings}

Up to this point I have been focusing on the effects of exposing business students to the standard economic model of human beings because this is the issue on which empirical research has concentrated. However, during their studies business students are also exposed to other models of human beings constructed by different types of social scientists. For instance, many theories of motivation use models of human decisions that assume that choices are determined by either external or internal factors. Examples are the hierarchy of needs model (Maslow, 1943), equity theory (Stacey, 1963) and expectancy theory (Vroom, 1964). Usually, such theories do not deny explicitly human freedom, they simply do not include it in their decision models. Two negative consequences of leaving freedom out of the picture are that students are often left with an idea of 'motivation' that is indistinguishable from outright manipulation ('How do I get them to act as I want them to?'), and that their sense of responsibility for their own actions tends to become blurred ('I was driven to act in that way ...').

There is no point in going here into all the different models to which business students may be exposed in the course of their studies. Still, in addition to those already discussed, it may be useful to mention stewardship theory (Donaldson \& Davis, 1991; Davis, Schoorman \& Donaldson, 1997), which depicts subordinates as collectivists, pro-organisational and trustworthy; institutional theory (Powell \& DiMaggio, 1991), which portrays the economic actions of individuals and organisations as determined by the institutional environment; and prospect theory (Kahneman \& Tversky, 1979; Tversky \& Kahneman, 1991) according to which the outcomes of risky prospects are evaluated by a value function characterised by referencedependence, loss aversion and diminishing sensitivity. My main interest here is simply to make the point that even though it is the harms associated with exposing business students to the economic model of man that are likely to be most pervasive and have been better documented, the basic issue is more general: Because of the very fact that they are scientific models rather than fully fleshed out descriptions, all the models used in the social sciences are extremely simplified descriptions of human beings.
And this is the main danger of using such models. Any business students who are not very mature intellectually are liable to confuse the simplified pictures presented by the models they are taught with accounts of human beings valid for all purposes and this is likely to have very serious consequences for people who will have to spend their professional lives working with flesh and blood human beings, and not with scientific models of human beings.

\section{The option of refashioning the social sciences}

From the point of view of management educators the issue is what is to be done if, as seems to be the case, exposing their students to standard treatments of economics, finance, strategy or organisational behaviour, has such harmful effects on them.

The proposal of some people - nothing if not ambitious - is to refashion the social sciences which provide the intellectual underpinnings of the management disciplines. Mitroff, for instance, advocates this position:

Without being fully aware or conscious of it, we have built and promulgated a series of theories with regard to business that are based on the worst characteristics of humans and the worst possible assumptions about human nature. Unless these characteristics and assumptions are abandoned and fully repudiated, we will only continue to turn out more Ken Lay's, Andrew Fastow's, Jeff Skillings's, etc. (2004: 185).

Etzioni (1988), Kahneman (2003) and their many followers are attempting this refashioning in respect of economics. Pérez López (1991 \& 1993) tried to set the bases for a similar reconstruction of organisation theory and Goshal (2005) advocated it for management theories more generally.

I see two problems with this approach: I do not really believe that there is anything inherently wrong with the current models to which business students are being exposed and, in any case, this is a proposal that is just too difficult to implement.

\section{Many models are not inherently defective}

As for the argument that there may well not be anything fundamentally wrong with the models themselves, or at least with many of them, it is important to emphasise that competent economists, psychologists or sociologists do not present their models as complete descriptions of human beings and the way they act. By their very nature, models are useful simplifications of a given reality, which highlight some aspects of that reality that are especially helpful or interesting for certain purposes, while leaving out other aspects. The features that are excluded from the model may perhaps be extremely important from certain points of view, but just happen to be of less interest for the purpose for which the model has been 
built. And a special characteristic of the models used in the social sciences as opposed to other models is that they are designed to be as simple as possible. Parsimony is an important feature of a good scientific model: other things being equal, the fewer elements the model contains, the better it is. In fact, this is a significant reason why the economic model of human beings is being increasingly used in other social sciences (Baron \& Hannan, 1994; Green \& Shapiro, 1994; Pfeffer, 2003; Posner, 2007; Kirchgässner, 2008): it is a very simple model which still manages to deliver a good capacity of prediction and explanation of human behaviour in the aggregate in many different types of situations.

Many social scientists insist that, in itself, the absence of realism of a model does not diminish the value of the theory that is built upon it; what matters to them is that simpler models allow sharper framing of hypothesis and easier mathematical treatment and that working with them they are able to generate valid predictions and illuminating explanations. There are several important issues conflated here, not least of the epistemology of science, and we cannot go into them in this article. The relevant point is simply that a model does not stand condemned by the mere fact that it does not incorporate all we know about a given entity or system. After all, Isaac Newton modelled planets and stars as points in space to which a mass is attached. Obviously, a point in space is not a realistic representation of a planet or a star, but this very simple model turned out to be extremely useful and Newtonian celestial mechanics became an extremely successful science. If we think of the models social scientists use as instruments which are designed for the specific purpose of - broadly speaking - providing explanatory power, we will not rush to discard them just because they produce some collateral harm when used (perhaps misused) for the different purpose of training business students.

\section{Changing substantially the various social sciences is a very long-term project}

The difficulty of refashioning the various social sciences should be obvious. It is one thing, for instance, to argue that moral factors should be explicitly considered in economics (Etzioni, 1989), or that economic models should be more realistic psychologically (Kahneman, 2003); it is a very different - and far more timeconsuming - task to actually implement that programme fully. Economics in its current state is the result of tens of thousands of papers, which discuss in detail a multitude of very specific questions, and of thousands of books, which integrate the results of all those individual papers and constantly shape and reshape the outlines of the discipline. To redo all that work on a different foundation, and to a level of quality and sophistication comparable with economics as it currently exists, will require decades of work by a very large number of economists. And in the meantime our students still need to be taught economics, finance, strategy, and so on.

Let us consider a specific example. Using the economic model of human beings, financial economists have succeeded in creating an options pricing model (Black \& Scholes, 1973; Merton, 1973), which actually succeeds in predicting quoted option prices in some contexts with an error of only 2\% (Rubinstein, 1985). It seems clear that it is not a practical option for responsible management educators not to teach this material to their students on the basis that it is built on the foundation of a model of human beings that could be harmful to them. The only realistic course of action is, while teaching it, to look for ways of counteracting any negative collateral effects that may follow from the students' exposure to it. Waiting until other economists succeed in developing a similarly useful financial tool on the basis of less dangerous foundations just does not seem to be a viable alternative.

\section{Counteracting the harmful effects of exposing students to the models of human nature developed by the social sciences}

It is crucial, therefore, before we throw out the baby with the bath water, to try to find practical ways to eliminate the negative side effects of exposing students to the models of human beings, which the social sciences use.

An important clue to what could be an appealing way forward is given in one of the studies quoted above on the effects of economic education. Frank et al. (1993) studied the effects on students of being exposed to a single one-semester introductory microeconomics course. For this purpose two groups of students, taught by two different instructors, were compared. The first instructor emphasised in his teaching how survival imperatives often militate against cooperation, while the second one did not emphasise such ideas to the same degree, but rather paid special attention in his lectures to institutional factors. After completing the course, the students of the first instructor gave significantly more cynical and less honest answers to a questionnaire than those who had studied with the second one.

This result suggests that what might be decisive is not so much the fact of using a given model, but rather the approach taken in using it. In other words, it indicates that management educators who are concerned by the findings we reported above about the effect of studying some social sciences on the moral character of students should pay more attention to the way these subjects are taught in their schools.

At this point I would like to suggest that perhaps much of the harmful effect on students who are exposed to highly reductive models of human nature could be avoided if more attention were paid to the total educational experience to which students are exposed 
and to the way in which those models are used in management education. Specifically, I think that some business schools fail to acquaint their students with broader and more inclusive views of human nature, which may help them to put in perspective the simpler models to which they are exposed in the course of their studies; and that a greater effort has to be made to make sure that those models and the theories built with their help are not used improperly.

\section{Providing a richer understanding of human nature}

The most obvious way to prevent students being negatively influenced by a very partial view of human beings is to provide them with a fuller and more realistic conception of human nature. It seems commonsensical that if students are exposed to a study in some depth of human beings in which features such as their ability to form abstract conceptions and to be moved by them, their need to 'see the point' of something in order to commit wholeheartedly to it, their freedom of choice, their susceptibility to be moved by emotions, their need for social bonds, and - not to be forgotten - the pull of their self-interest, all are given due consideration, it will be more difficult for them to assume uncritically that the models of human nature and human behaviour which are used in some disciplines provide a complete picture of human nature.

Obviously, such a fleshed-out description of human beings is too complex to be used as a model on the basis of which to make determinate predictions of how human beings will act in specific circumstances, and this is the reason why social scientists use much simpler models. But providing students with a fuller view of human beings will help them realise the limitations of the thinned out models to which they are exposed in the course of their studies when they are used for other purposes than those for which they were originally devised.

In practical terms, this is not especially difficult to do. A way of doing it would be to introduce in the programme a course, or even a half-course, on philosophical anthropology in which a more inclusive conception of human nature is discussed in some detail.

One could hope instead to provide students with a wider and more balanced view of human nature through the use of many different narrow models that would be complementary to each other. In practice, however, this solution is unlikely to work. A reason is that by itself, and without the benefit of a more comprehensive and integrated view of human beings, such as is provided by philosophical anthropology, that solution is likely to generate greater confusion in the minds of the students. A second reason is that the homo economicus model is used to such a great extent in the curriculum of the typical business school, and is having such an impact in other social sciences beyond economics, that it is unrealistic to expect that its impact may be adequately balanced by other models.

\section{Not misusing models}

Besides providing an understanding of human nature that goes beyond the extreme simplifications of many of the models used in the social sciences, it is also important to make a correct use of models. This involves both taking a more critical stance in assessing the practical advice that often is presented as following from those models and paying more explicit attention to the issues involved in the 'application' of models.

\section{Not moving uncritically from models to prescription}

Many management educators and popular management writers make the serious error of deriving from the models they use definite - and often unqualified - prescriptions about the way practitioners should act in the real world. At this point, the fact that the model of man they use is overly reductive often leads to unsound advice.

There is nothing wrong, for instance, with building models that depict human beings as being moved by the rational pursuit of their own individual interests, and there is nothing wrong with building theory on the basis of such models. But there is a lot wrong with moving uncritically from such models and theories to the conclusion that that is how all (or most) human beings act all (or most) of the time, and with advising practitioners to act on the basis of such a conclusion.

To give a specific example, agency theory is a management theory which is based on the economic model of human beings and which has been especially influential in the areas of corporate governance, organisational design and executive compensation. Agency theory indicates, for instance, that a sharp divergence of interests can be expected to obtain in most situations between shareholders and managers and that this divergence of interests should be curbed, among other ways, by imposing control structures upon managers and other staff of business firms. In the absence of these controlling mechanisms, agency theory indicates that managers and staff can be expected to pursue their own interests, maximising their own power, income, prestige and perquisites, at the expense of the organisation, which employs them (Jensen \& Meckling, 1976).

While agency theory captures part of the truth about human beings and their behaviour, it does not capture the whole truth. In fact many human beings do not behave all of the time as self-serving opportunists.

However, when organisations are governed in accordance with advice derived from agency theory, dysfunctional results may follow. Even the most committed employees are liable to stop being so committed if they find themselves under tight control, always mistrusted, and constantly being curbed in their initiatives. In relation to such people, agency theory becomes a self-fulfilling prophecy: it assumes that people 
cannot be trusted and because of that recommends that they be managed in ways that make them become actually untrustworthy, thereby validating the prophecy! (Ghoshal \& Moran, 1996; Ferraro et al., 2005).

For the avoidance of doubt, I would like to stress that I am not trying to argue that agency theory is wrong. My main points are simply that it is extremely dangerous to assume uncritically that the model of human beings used in agency theory is a description of real human beings, which is adequate for all purposes, and that therefore the practical advice offered by agency theorists should be most carefully scrutinised before applying it. Similar points could be made in relation to other economic theories which have been applied to management issues such as transaction costs analysis and population ecology: in so far as they share the same fundamental model of man, they tend to create the same problems in practice.

\section{Helping students move from models to practical problem solving}

Whether the use of overly simplified models of human nature in management education will harm students is likely to depend on how faithful that education is to its own espoused aims. If the instruction given consists for the most part in explaining an assortment of theories from which a long list of 'how to do it' recipes are derived, the danger is likely to be grave indeed. But in so far as the learning experience is truly an education for management, which aims at developing the students' judgment and their capacity for handling real world situations, the dangers are likely to be significantly attenuated.

Let me refer again, as an example, to the issue of teaching options pricing in an MBA programme, which has already been mentioned above. One way of doing this - unhappily only too frequent - is that all the students get is an explanation of the theory - and bound with it what the students perceive to be an endorsement of the economic model of man on which it is based - and a series of 'exercises' on how to 'apply' the option pricing model to different situations. If things are handled in this way the students will have been 'indoctrinated' a little more in the uncritical acceptance of that model of man as a comprehensive description of human beings, useful for all purposes (even if that was not the aim of their instructors), and some of them will become a little more self-interested in the process. But this is not only poor moral education, it is also very poor management education.

An educator who is conscious that her students will not be able to manage organisations by applying a long list of formulas will go about things in a different way. He will still teach the relevant theory and models, and will provide some exercises on their 'application'. But beyond that, he will also help the students to consider how to use the theory and the models in the world of practice. This may be done through the use of case studies or in other ways, but the essential point is that the educator will try to help his students to make the transition from the highly constrained world of scientific models to the much richer, and far more complicated, professional world in which students will have to work. In that professional world, a flesh-andblood human being will not automatically choose the option, which has the highest value according to the model. The model does not take into account factors like the trustworthiness of the other party, the decisionmaker's special areas of experience and expertise, the fact that perhaps she had previously committed herself to a certain course of action, and the additional fact that perhaps that day was her husband's birthday and she wanted to be back home early, to name just a few. For instance, if the management educator is using the case method, it is likely that during the teaching session some time will have been devoted to 'doing the numbers' and considering the results of applying the pricing model to the different alternatives; but much, if not most, of the discussion is likely to centre around all those other factors in the situation described by the case study which are left out of account by the model, most especially around the fact that actual human beings are not like the model assumes they are. The end result of this type of discussion is not likely to be a strengthening of the students' uncritical acceptance of a simplified model of human nature, but rather some additional insight into its rich complexity.

\section{Conclusion}

There is evidence that more self-interested students are drawn to choosing economics and business courses and that being exposed repeatedly to the economic model of human beings during their studies tends to accentuate that disposition in them.

I have argued in this article that the widespread use of social science models in business education presents a more general problem. Such models are of necessity highly reductive and frequent exposure to them may well lead some students to form an impression that human beings are like the models they have learned about describe them, although this will only be the case where intensive use is made of such models.

There have been calls to address this situation by either not using such models - or giving them less prominence - in the education of business students, or by recasting the social sciences and management disciplines on the basis of different models. I have examined such proposals in this article and I conclude that they may be unjustified as often there is nothing wrong with the models themselves and that in any case they cannot solve our problems within a realistic time frame. 
I have suggested some strategies for action which in my view offer better prospects of success: offering the students as part of their academic programme a course in which they are exposed to a richer and more finely grained conception of human nature; and making certain that whenever an overly reductive model of human beings is taught, students have a full opportunity to reflect on some of the features of human beings which are not included in that model.

\section{Acknowledgements}

I wish to thank three anonymous referees for their very helpful comments.

\section{References}

Aspen Institute. 2001. Where will they lead? MBA student attitudes about business and society. New York: Aspen Institute for Social Innovation Through Business.

Baron, J.N. \& Hannan, M.T. 1994. The impact of economics on contemporary sociology. Journal of Economic Literature, 32: 1111-1146.

Black, F. \& Scholes, M. 1973. The pricing of options and corporate liabilities. Journal of Political Economy, 81: 637-654.

Blais, A. \& Young, R. 1999. Why do people vote? An experiment in rationality. Public Choice, 99: 39-55.

Brennan, M. 1994. Incentives, rationality, and society. Journal of Applied Corporate Finance, 7: 31-39.

Cadsby, C.B. \& Maynes, E. 1998. Choosing between a socially efficient and free-riding equilibrium: Nurses versus economics and business students. Journal of Economic Behavior and Organization, 37: 183-192.

Carter, J.R. \& Irons, M.D. 1991. Are economists different, and if so why?. Journal of Economic Perspectives, 5(2): 171-177.

Davis, J.H., Schoorman, F.D. \& Donaldson, L. 1997. Toward a stewardship theory of management. Academy of Management Review, 22(1): 20-47.

Davis, L. 1987. Moral Judgement Development of Graduate Management Students in Two Cultures. Minnesota and Singapore. University of Minnesota: unpublished dissertation.

Dawes, R. 1980. Social dilemmas. Annual Review of Psychology, 31: 163-193.

Dienesch, R.M. \& Liden, R.C. 1986. Leader-member exchange model of leadership: A critique and further development. Academy of Management Review, 11: 618-634.

Donaldson, L. \& Davis, J.H. 1991. Stewardship theory or agency theory: CEO governance and shareholder returns. Australian Journal of Management, 16: 49-64.

Etzioni, A. 1988. The moral dimension: Toward a new economics. New York: the Free Press.

Ferraro, F., Pfeffer, J. \& Sutton, R.I. 2005. Economics language and assumptions: How theories can become self-fulfilling. Academy of Management Review, 30(1): 8-24.

Frank, B. \& Schulze, G.G. 2000. Does economics make citizens corrupt? Journal of Economic Behavior and Organization, 43: 101-113.
Frank, R.H., Gilovich, T. \& Regan, D.T. 1993. Does studying economics inhibit cooperation? Journal of Economic Perspectives, 7(2): 159-171.

Frey, B.S. \& Meier, S. 2003. Are political economists selfish and indoctrinated? Evidence from a natural experiment. Economic Inquiry, 41(3): 448-462.

Gandal, N., Roccas, S., Sagiv, L. \& Wrzesniewski, A. 2005. Personal value priorities of economists. Human Relations, 58: 1227-1252.

Goshal, S. 2005. Bad management theories are destroying good management practices. Academy of Management Learning and Education, 4(1): 75-91.

Ghoshal, S. \& Moran, P. 1996. Bad for practice: A critique of the transaction cost theory. Academy of Management Review, 21(1): 13-47.

Graen, G.B. \& Uhl-Bien, M. 1995. Relationship-based approach to leadership: Development of leader-member Exchange (LMX) theory of leadership over 25 years. Leadership Quarterly, 6: 219-247.

Green, D. P. \& Shapiro, I. 1994. Pathologies of rational choice theory: A critique of applications in political science. New Haven, CT: Yale University Press.

Henrich, J., Boyd, R., Bowles. S., Camerer, C., Fehr, E., Gintis, H. \& McElreath, R. 2001. In search of Homo economicus: Behavioral experiments in 15 small-scale societies. American Economic Review, 91: 73-78.

Jensen, M.C. \& Meckling, W.H. 1976. Theory of the firm: Managerial behaviour, agency costs and ownership structure. Journal of Financial Economics, 3: 305-360.

Jensen, M.C. \& Meckling, W.H. 1994. The nature of man. Journal of Applied Corporate Finance, 7(2): 4-19.

Kahneman, D., Knetsch, J.L. \& Thaler, R.A. 1986. Fairness and the assumptions of economics. Journal of Business, 59(4): 285-305.

Kahneman, D \& Tversky, A. 1979. Prospect theory: An analysis of decision under risk. Econometrica, 47: 263-91.

Kahneman, D. 2003. A psychological perspective on economics. American Economic Review, 93: 162-168.

Kirchgässner, G. 2008. The economic model of behavior and its applications in economics and other social sciences. New York: Springer.

Leavitt, H.J. 1989. Educating our MBAs: On teaching what we haven't taught. California Management Review, 31(3): 38-50.

Mangan, K.S. 2002. The ethics of business schools. Chronicle of Higher Education, 49(4): A14.

Marwell, G. \& Ames, R.E. 1981. Economists free ride, does anyone else? Journal of Public Economics, 15: 295-310.

Maslow, A. 1943. A theory of human motivation. Psychological Review, 50: 370-396

McCabe, D.L., Butterfield, K.D. \& Trevino, L.K. 2006. Academic dishonesty in graduate business programmes: Prevalence, causes and proposed action. Academy of Management Learning \& Education, 5(3): 294-305.

Merton, R.C. 1973. Theory of rational option pricing. Bell Journal of Economics and Management Science, 4: 141-183.

Miller, D.T. 1999. The norm of self-interest. American Psychologist, 54(12): 1053-1060.

Mintzberg, H. 2004. Managers, not MBAs. London: Prentice Hall.

Mitroff, I.I. 2004. An open letter to the deans and the faculties of American business schools. Journal of Business Ethics, 54: 185-189. 
Pérez López, J.A. 1991. Teoría de la acción humana en las organizaciones. La acción personal. Madrid: Rialp.

Pérez López, J.A. 1993. Fundamentos de la dirección de empresas. Madrid: Rialp.

Pfeffer, J. 1997. New directions for organization theory: Problems and prospects. New York: Oxford University Press.

Posner, R.A. 2007. Economic Analysis of Law (7th edition). Aspen, CO: Law and Business.

Powell, W.W. \& DiMaggio, P. (eds.) 1991. The new institutionalism in organizational analysis. Chicago, IL: Universisty of Chicago Press.

Rubinstein, A. 2006. A sceptics's comment on the study of economics. The Economic Journal, 116(3): 1-9.

Rubinstein, M. 1985. Nonparametric tests of alternative option pricing models using all reported trades and quotes on the 30 most active CBOE option classes from August 23, 1976 through August 31, 1978. Journal of Finance, 40: 455-480.

Sargent. 1986. Ego development and choice of major field in college. Paper presented at the 1986 meeting of the Rocky Mountain Business Law Association.

Schneider, B. 1987. The people make the place. Personnel Psychology, 40: 437-453.

Schneider, B., Goldstein, H.W. \& Smith, D.B. 1995. The ASA framework: An update. Personnel Psychology, 48: 747-779.

Selten, R. \& Ockenfels, A. 1998. An experimental solidarity game. Journal of Economic Behaviour and Organization, 34: 517-539.

Sen, A. 1977. Rational foos: A critique of the behavioral foundations of economic theory. Philosophy and Public Affairs, 6: 317-344.

Simon, H. 1985. Human nature in politics: The dialogue of psychology with political science. American Political Science Review, 79: 293-304.
Stacey, A.J. 1963. Toward an understanding of inequity. Journal of Abnormal and Social Psychology, 67: 422-436.

Tetlock, P.E. 2000. Cognitive biases and organizational correctives: Do both disease and cure depend on the politics of the beholder? Administrative Science Quarterly, 45: 293-329.

Tversky, A. \& Kahneman, D. 1991. Loss Aversion in riskless choice: A reference-dependent model. The Quarterly Journal of Economics, 1039-1061.

Vroom, V.H. 1964. Work and motivation. New York: Wiley.

Walsh, W.B. \& Holland, J.L. 1992. A theory of personality types and work environments. In W.B. Walsh, K.H. Craik \& R.H. Price (eds.) Person-environment psychology: Models and perspectives, 35-69. Hillsdale, NJ: Lawrence Erlbaum Associates.

Williams, R.J., Barrett, J.D., \& Brabston, M. 2000. Managers' business school education and military service: Possible links to corporate criminal activity. Human Relations, 53: 691-712.

Yezer, A., Goldfarb, R. \& Poppen. P. 1996. Does studying economics discourage cooperation? Watch what we do, not what we say or how we play. Journal of Economic Perspectives, 10(1): 177-186.

Address correspondence to: Juan Elegido Lagos Business School Pan-African University 2 Ahmed Onibudo Street Victoria Island, Lagos Nigeria e-mail: jelegido@lbs.edu.ng 
Reproduced with permission of the copyright owner. Further reproduction prohibited without permission. 